\title{
Importance and Improvements in Teaching-Learning process through Effective Evaluation Methodologies
}

Tripathi, Ramna ${ }^{1}$ and Kumar, Akhilesh ${ }^{2}$

${ }^{1}$ Department of Physics, THDC- Institute of Hydropower Engineering and Technology B. Puram, Tehri, Uttarakhand, India

${ }^{2}$ Department of Physics, Govt. Girls College, Rajajipuram, Lucknow, UP, India

Corresponding Author: ramna tripathi@yahoo.co.in

\section{A R T I C L E I N F O}

Received: 22 June 2018 | Accepted: 12 September 2018 | Published Online: 31 December 2018

DOI: $10.31786 / 09756272.18 .9 .2 .202$

EOI: $10.11208 /$ essence.18.9.2.202

Article is an Open Access Publication.

This work is licensed under Attribution-Non Commercial 4.0 International

(https://creativecommons.org/licenses/by/4.0/)

CThe Authors (2018). Publishing Rights @ MANU—ICMANU \& ESSENCE—IJERC.

\section{A B S T R A C T}

With the advancement of technologies, methods of teaching, learning and evaluation in higher education need modification from the current scenario. Teaching is key component in educational planning, which is one of the most important factor in steering educational plans. Despite the importance of good teaching, the outcomes are far from ideal. This paper deals to investigate effective teaching, learning and evaluation for higher education. Rapid changes in the modern world has caused the Higher Education System to face overabundance of challenges. Therefore, the training of more eager and thoughtful individuals in interdisciplinary fields is vital. Research and exploration to figure out effective teaching and learning methods are one of the most important necessities in the modern educational systems. Professors have a determining role in training eager and thoughtful individuals. Universities and colleges are the places where new ideas sprout; roots strike deep and grows tall and sturdy. These places embrace the entire universe of knowledge. These are the spaces where creative minds converge, interact with each other and construct visions for noble realities. Established notions of truth are challenged in the pursuit of knowledge.

\section{K E Y W O R D S}

Teaching | Learning | Evaluation

\section{I T A T I O N}

Tripathi, Ramna and Kumar, Akhilesh (2018): Importance and Improvements in Teaching-Learning process through Effective Evaluation Methodologies. ESSENCE Int. J. Env. Rehab. Conserv. IX (1): $7-16$. 


\section{Introduction}

Rapid changes of modern world have caused the Higher Education System to face a variety of challenges. Universities and Colleges are the places where new ideas germinate; roots goes deep down and grow tall and sturdy trees bear the fruits of attractive outcomes. These are unique spaces where the entire universe of education and knowledge can be served. Creative minds converge here, interact with each other and desired realities are created. Established notions of truth are challenged for the deeper pursuit of knowledge. In order to accomplish this task, getting help from experienced and willing teachers is essential. Training more eager, thoughtful and individuals in interdisciplinary fields has become necessary. Therefore, research and exploration to figure out useful and effective teaching and learning methods are one of the most important requirements of education system today. Professors have to play a decisive role in training people in these fields.

Given the quality of education, attention of student towards education as a main product that is expected from education system is in much greater demand as compared to past. There has always been an importance of research and teaching quality and to establishing a relationship between these two before making any decision. Studies show that existing levels of attention towards research in colleges and universities does not meet the demands of improvements in educational quality. Consideration of research in higher education is regarded as a major factor in education. For their instruction, educators must pay attention to learners and learning approaches. Together with these two factors, the educators must move forward to adopt and practice new teaching approaches. In the traditional approach, instruction was teacher-centered and the students are expected to receive and retain those instructions. This is the time when instruction must change into a method in which needs of the student are considered and as a result active behavioural changes takes place in them.

A large number of graduated students especially bachelor degree holders do not feel ready enough to work in their related fields. Being dissatisfied with the current situation at academic institutions and then making decision to upgrade requires abundant research and assistance from the experts and managing bodies of institutions. Dedicating the aforementioned support is necessary in the current situation prevailing in India. It is a fact that qualitative studies has ever been carried out in education to draw in-depth reports by recognized universities. Limited due to this reason, global student-centered methods are explored and studied and the ideas of experienced university faculties has been incorporated. In-class observations and interviews are also combined in the study. Ideas of the faculty ideas about teaching method could be itemized just through a qualitative study. An efficient teaching method, its barriers and requirements are considered in the current paper. The importance and improvement of teaching, learning and evaluation method are discussed in detail

\section{Teaching}

Teaching means the act, practice, or profession of a teacher. It is the process giving shape one's thought and action through instructions and/or performing practices that lead to a new behaviour and capacity in the students. Teaching can be conducted using several methods based on the nature of subject and customised according to students.

\section{Teaching Principles}

Teaching is a complex, multifaceted activity which often requires flexibly juggling with numerous tasks and goals simultaneously. Following are small but dominant set of principles that can make teaching both more effective and efficient. They support student learning and minimize the need for revising materials, content, 
and policies. While implementing these principles require a commitment of time and efforts, in turn these often save time and energy.

A variety of student characteristics affects learning. For example, cultural and generational backgrounds of students influence how they see the world. Disciplinary backgrounds influences students to approach problems in differently. Prior subject knowledge (both accurate and inaccurate aspects) determines the absorption of new learning.

Effective teaching methodology involves acquiring relevant knowledge about students and using it to inform course design and classroom teachings.

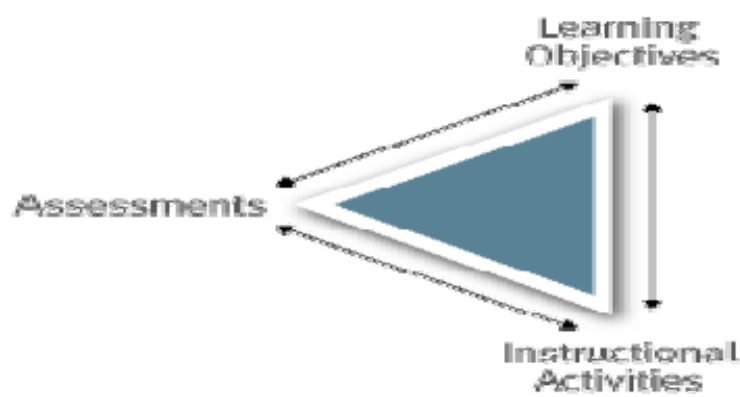

Effective teaching involves aligning all three major components of instruction: learning objectives, assessments and instructional activities:

Taking time to perform these activities upfront saves time in the end and leads to a better course delivery. Teaching is more effective and student learning is enhanced when,

(a) Instructors, articulate a clear set of learning objectives (i.e., the knowledge and skills that a teacher expect students to establish);

(b) These instructional activities (e.g., case studies, labs, discussions, readings) support learning goals by providing goal-oriented activities; and

(c) Assessments (e.g., tests, papers, problem sets and performances) provide an opportunity for students to demonstrate and practice the knowledge and skills articulated in goals. For instructors it offers targeted feedback that can further guide the teaching.

Effective teaching involves articulating explicit expectations regarding learning objectives and policies.

There is an astonishing variation in what is expected from students across classrooms and even within a given discipline. For example, what constitutes evidence may differ greatly across courses, what is permissible collaboration in one course may be considered cheating in another course. As a result, expectations of the students may not match the expectation of the teachers. It is important to be clear about expectations and communicating them explicitly to students help their learning productively and perform better. Articulating learning objectives (i.e., the knowledge and skills that is expected from students to demonstrate by the end of a course) gives students a clear target to aim for and enables them to monitor progress along the way. Similarly, being explicit about course policies (e.g., on class participation, laptop use, and late assignment) in the syllabus and in class allows resolution of differences early on which tends to reduce conflicts and tensions that may arise. To sum it up, being explicit leads to a more productive learning environment for students.

Effective teaching involves prioritizing the knowledge and skills that choose to focus on.

Coverage of wide unrelated topics in a single course is enemy of the learning process. Don't try to cover too much in a single course. Too many topics work against learning, thus it is necessary for teachers to make decisions about what will be and will not be included in a course. It involves (a) recognizing the parameters of the course (e.g., class size, students' backgrounds and experiences, course position in the curriculum sequence, number of course units), (b) setting our priorities for student learning, and (c) determining a set of objectives that can be reasonably accomplished. 


\section{Effective teaching involves recognizing and overcoming blind spots.}

Teachers as specialists tend to access and spread over knowledge instinctively (e.g., make connections, draw on relevant bodies of knowledge, and choose appropriate strategies) and hence they often skip critical steps when they are teaching. Students, on the other hand, don't have sufficient background and experience to make these leaps thus they get confused and uninterested. They draw incorrect conclusions, or fail to develop important and required skills. Students expect instructors to break tasks into component steps, explain connections clearly and processes in detail. However, it is difficult for specialists to consistently do this. They need to identify and explicitly communicate to students the knowledge and skills they have, so that students can observe their teachers thinking and applying the knowledge themselves.

\section{Effective teaching involves adopting appropriate teaching roles to support learning goals.}

Notwithstanding students are in the end responsible for their own learning, the role teachers are critical in guiding student's thinking and behaviour. They can undertake a variety of roles such as synthesizer, moderator, challenger and commentator in their teaching. These roles must be chosen to serve learning objectives and to support instructional activity. For example, when the objective for students is to be able to analyze arguments from a case or written text, the most productive instructor role might be to frame, guide and moderate the inclusive and detailed discussion. It is the objective of teacher is to help students learn to preserve their positions or creative choices when they present their work. Teacher's role might also be to challenge students to explain their decisions and consider alternative perspectives. Such roles can be continuous or adjustable across the timelines depending on the learning objectives.

\section{Effective teaching involves progressively refining courses based on reflection and feedback.}

Teaching requires a lot of continues adaptations. Teachers need to frequently reflect on their teaching and be ready to make changes when appropriate (e.g., something is not working, try something new) since the student population has changed and there are emerging issues in the world. Knowing what and how to change requires examining relevant information for teaching effectiveness. Much of this information already exists such as the works of previous students, course evaluations of previous semesters and dynamics of class participation. Teachers would require to seek additional feedback with the help from university teaching centre. These supports ranges from interpreting early course evaluations, conducting focus group studies, designing preand post-tests. Based on such evaluations, teachers might modify the learning objectives, course content, structure and format of courses and adjust the teaching accordingly. Small, purposeful changes driven by constant feedbacks are most likely to be manageable and effective.

\section{Learning}

It is the process of acquiring new or modifying

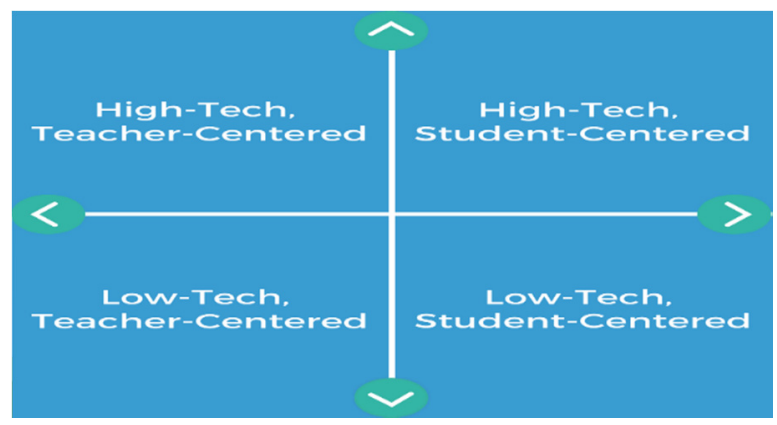

existing knowledge, behaviors, skills, values and preferences. It can be organized into four categories based on two major parameters: teacher-centred approach versus student- centred approach, and high-tech material use versus lowtech material use. 


\section{Teacher-Centered Approach to Teaching}

To interpret in better way, teachers are the main authority in a teacher-centered instruction model. Students are viewed as "empty vessels" who passively receive knowledge from their teachers through lectures and direct instructions with the objective of positive results from testing and assessment. In this style, teaching and assessment are viewed as two separate entities and learning of students are measured through objectively scored tests and assessments.

\section{Student-Centered Approach to Learning}

While teachers are still an authority in studentcentered teaching model. Here, teachers and students play equally active role in the learning process. Primary role of the teacher is to coach and facilitate student learning and overall understanding of comprehension course material and to measure learning of students through both formal and informal methods of assessment, like group projects, portfolios and class participation. In the student-centered approach, teaching and assessment are connected because learning of the student is continuously measured during the process.

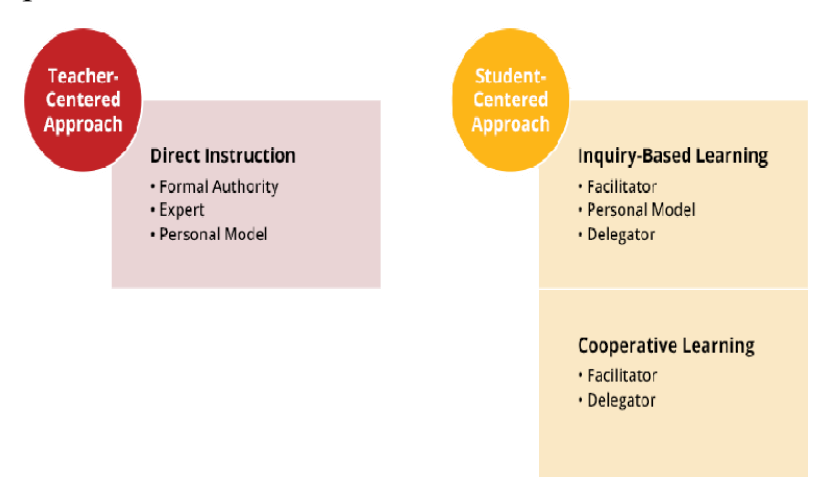

\section{High-Tech Approach to Learning}

Improvements and innovations in modern technology have driven the education sector in the last few decades. The high tech approach to learning employs different technologies to support students in their classroom learning. Many educators use computers and tablets in the classroom, and others use internet to assign homework. Internet also provides unlimited resources for teaching and learning. Teachers may also utilize internet in order to connect their students with people from around the world.

Below are some tech tools used in classrooms today:

- G Suite (Gmail, Docs, Drive, and Calendar)

- Tablets/laptops

- Gamification software (such as 3DGameLab and Class craft)

- Education-focused social media platforms

- Technology for accessibility for students with disabilities

\section{Low-Tech Approach to Learning}

While technology has altered education, many educators prefer to use a more traditional, low tech-approach to teaching. These learning styles requires physical presence and interaction between educator and students. Some researchers have shown that low-tech classrooms may boost learning. These researches suggest, students who take handwritten notes have better recall than students who take typed notes. Another downside of technology in the classroom may be that students who get exposed to spell check and autocorrect features at an early age may be weaker in spelling and writing skills. Ultimately, tailoring the learning experience to different types of learners is incredibly important and sometimes students work better with a low-tech approach.

Here are some examples of low technology usage in different teaching methodologies:

- Kinesthetic learners have a need for movement when learning. Teachers should allow students to move around, speak with hands and gestures.

- Expeditionary learning involves "learning by doing" and participating in an active experience. Students participate in fieldwork, learning expeditions, projects or case studies to be able to apply knowledge $\mathrm{g}$ in gained classroom to the real life scenarios rather than learning in the virtual world. 
- Many types of vocational or practical training cannot be learned virtually, whether it be a laboratory experiment or woodworking.

\section{Evaluation Systems}

In every area of life the process of evaluation takes place in some or the other manner. If the evaluation process is eliminated from human life then perhaps the aim of life may be lost. It is only through evaluation that one can discriminate between good and bad or right and wrong. The whole sequence of social development spins around evaluation processes. In education how much a child has succeeded in his aims, can only be determined through evaluation. Thus there is a close relationship between evaluation and aims (8).

The term evaluation conveys several meanings in education and psychology.

\section{Different authors have different notions of evaluation}

1. Encyclopaedia of Education Research: To measure means to observe or determine the magnitude of variate; evaluation means assessment or appraisal.

2. James M. Bradfield: Evaluation is the assignment of symbols to phenomenon, in order to characterise the worth or value of a phenomenon, usually with reference to some social, cultural or scientific standards.

3. Gronlund and Linn: Evaluation is a systematic process of collecting, analysing and interpreting information to determine the extent to which students are achieving instructional objectives.

Perhaps the most extended definition of evaluation was given by Beeby (1977), who described evaluation as "the systematic collection and interpretation of evidence leading as a part of process to a judgement of value with a view to action."

In this definition, there are the following four key elements:

\section{a. Systematic collection of evidence}

The first component of 'systematic collection' means whatever information is gathered should be acquired in a systematic and planned way with a reasonable level of precision.

\section{b. Its interpretation}

The second element in Beeby's definition, 'interpretation of evidence', is an important aspect of evaluation process. The mere collection of evidence does not on its own establishes evaluation work. The information collected for evaluation purpose for an educational program must be judiciously interpreted. Sometimes, uninterpreted evidence is presented to indicate the presence (or absence) of quality in an educational project.

For example, in a two year program in computers, it was noted that almost two-third of each entering class failed to complete the two years program. On closer checking it was found that most of the dropouts after one year were offered good jobs by companies. The managers of companies felt that the one year of training was not only more than adequate for entry and second level positions but also provided the foundation for further career advancements. Under such circumstances, the dropout rate before program completion was no indication of program failure or deficiency.

\section{c. Judgement of value}

The third element of Beeby's definition, 'judgement of value', considers the evaluation process far beyond the level of description of what is happening in an educational project, it essentially requires judgements about the worth of an educational efforts.

Hence, evaluation process not only comprises gathering and interpreting information about how well an educational project is performing in attainment of goals but assessing the goals itself. It involves questioning, how well a project is helping to meet broader educational goals. 


\section{d. With a view to action}

The last component of Beeby's definition, 'with a view to action', presents the distinction between conclusion-oriented undertaking that results in only in judgement of value with no specific reference to action and decision-oriented undertaking that is deliberately done for the sake of future action.

Educational evaluation is evidently a decisionoriented approach which is undertaken with the purpose that some action will take place as a result. It is intended to guide better policies and practices in education.

Education is treated as an investment in human beings for the development of human resources, skills, motivation, knowledge and attitude. Evaluation helps to build an educational project, assess its successes and improve its effectiveness. It serves as an in-built mirror within the program to time-to-time review the progress in learning. It also provides valuable feedback on design and implementation of the program. Therefore, evaluation plays a significant role in any educational program. Evaluation has a vast role in teaching-learning process.

Evaluation in one form or the other is expected in teaching-learning. In all fields of education judgements need to be made. It helps teachers and learners both in improving teaching and learning simultaneously. Evaluation is a continuous process done as a periodic exercise. It helps in forming the values of judgement, educational status and accomplishment for student. In learning, it contributes to formulation of objectives, designing learning experiences and assessment of learner performance. Also, it is very useful to bring enhancements in teaching and curriculum. It provides accountability in the society, parents and into the education system.

Educational evaluation is the evaluation process of describing and assessing multiple aspects of an educational process. There are two common purposes in educational evaluation which are at times also in conflict with each one another. Educational evaluation is a professional activity which they need to undertake if they intend to continuously review and enhance the learning they wish to facilitate. There is no ingenuous system for evaluating the quality of faculty research and teaching. Thinking carefully about the purposes of evaluation and constructing multiple methods of evaluation that apply to those purposes, one can devise evaluation systems that are reliable, valid, and fair. Equally significant is the process of discussing and crafting evaluation systems focuses attention on the practice of good teaching and helps in creating a culture in which learning and teaching is highly valued.

\section{Here is the list in which evaluation is required:}

\section{a. Teaching}

Evaluation involves with assessing the effectiveness of teaching, teaching strategies, methods and techniques used for teaching. It also provides feedback to teachers about their teaching and learners about their learning.

\section{b. Curriculum}

Improvements in courses and curriculum, texts and teaching materials can be brought about with the help of evaluation.

\section{c. Parents}

Evaluation mainly demonstrates itself in need for regular reporting to parents. Parents are eager to know about the educational progress of their children and evaluation alone can assess the students' progress from time to time.

\section{d. Society}

Evaluation provides accountability to society in terms of demands and requirements of the market.

In brief, evaluation is a very important necessity for the education system. Evaluation plays an effective role in questioning or challenging the objectives. It achieves various purposes in education systems such as quality control, 
selection or entrance to higher grades. It also aids decisions taking about success in specific future activities and delivers guidance for higher studies and occupation. Many educationists regard evaluation to be almost synonymous with learner appraisal with evaluation involving expanded role.

An illustration explaining the role of evaluation in the teaching-learning process is given below which role of evaluation in the Teaching-Learning process:

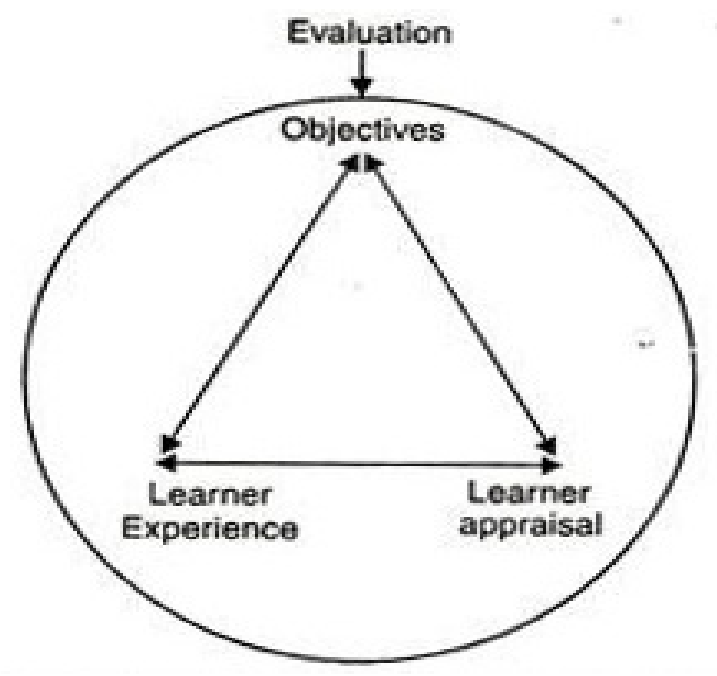

\section{Characteristics of Evaluation}

The analysis of all the above definitions makes us able to draw following aspects of evaluation:

1. Learning is more important than teaching. Teaching has no value if it does not result in learning on the part of students. It helps the teacher to determine, evaluate and refine their instructional techniques and in setting-up, refining and clarifying the objectives.

2. Objectives and learning experiences accordingly should navigate students towards accomplishment of learning goals. It helps a student in encouraging good study habits, in increasing motivation and in developing abilities and skills, in knowing the results of progress and in getting appropriate feedback.
3. Evaluation is an ongoing process. It is a mistaken belief that the evaluation procedure follows the teaching-learning process. In an idyllic situation, teaching- learning process in one hand and evaluation process on the other hand go hand-in-hand. Evaluation stresses on broad personality changes and major objectives of educational program. Therefore, it includes not only subject-matter achievements but also attitudes, interests and ideals, ways of thinking, work habits and social adaptability.

4. Evaluation system constantly undertakes educational objectives to be previously identified and defined. That is why teachers are expected not to lose sight of educational objectives while planning and executing teaching-learning process either in the classroom or outside of it. A comprehensive program of evaluation involves the use of many procedures such as analyticosynthetic, heuristic, experimental, lecture, etc. A great variety of tests such as essay type, objective type, etc. and other necessary techniques (for example, socio-metric, controlled-observation techniques, etc.

5. Evaluation system suggests an orderly procedure which removes casual and uncontrolled observation of students.

6. To assess the students and their attained development through education is evaluation.

7. Evaluation is the determination of the synchronicity between performance and objectives.

\section{Functions of Successful Evaluation Process}

Evaluation has the following functions:

\section{Placement Functions}

a. Evaluation helps to understand the entry behaviour of the children in all salutations.

b. It helps to start special instructional programs.

c. To support the customization of instruction.

d. It also helps in selecting students for higher studies, other vocations or specialised courses. 


\section{Instructional Functions}

a. A prearranged evaluation system help teachers in deciding and developing ways, methods and techniques of teaching. Education being a complex process. Thus, there is a great need of constant evaluation of its processes and products. It helps to design better educational programs.

b. It helps to formulate and reformulate suitable and realistic objectives for instruction. To plan appropriate and adequate learning strategies.

c. Helps in improving instruction and to plan appropriate and adequate techniques of instruction. It also aids in the improvement of curriculum and quality of teachers.

d. To evaluate diverse educational practices.

\section{Diagnostic Functions}

a. Evaluation has to identify weak points in the program in addition to weakness of the students.

b. To suggest applicable corrective programs and adopt instruction to the different needs of students. To evaluate the progress of these weak students in terms of their capacity, ability and goal. It also helps us to undertake special instructional programs like enrichment program, for the bright and remedial programs for the backward.

c. The aptitude, interest and intelligence are also to be recognised in each student so that they may be energised towards a right direction. It helps a teacher to know his students in details. Today, education is child-cantered. Student's abilities, interest, aptitude, attitude etc., are to be properly studied so as to arrange instruction accordingly.

\section{Predictive functions}

a. To discover latent abilities and aptitudes amongst the learners.

b. To forecast the future achievement of the students.

c. It helps the students in selecting the right electives.

\section{Administrative Functions}

a. Helps in developing a comprehensive criterion tests.

b. To adopt better educational policy and decision making.

c. To draw relative statement on the performance of students.

d. Helps to classify students in different convenient groups.

e. To promote students to next higher grades.

f. To have appropriate placements.

g. To evaluate the supervisory practices.

h. Helps to examine the efficiency of teachers in providing suitable learning experiences.

i. To mobilise public opinion and to improve public relations.

\section{Guidance Functions}

a. Enables a learner to know his pace of learning and lapses in his learning.

b. Helps a teacher to know the children in details and to provide necessary educational, vocational and personal guidance.

c. Assists a person in making decisions about courses and their careers.

\section{Motivation Functions}

a. To motivate, direct, inspire and involve the students in learning.

b. To reward their learning and in-turn to motivate them towards study.

\section{Development Functions}

a. Gives feedback and reinforcements to teacher, students and teaching learning processes.

b. Assists in the modification and improvement of the teaching strategies and learning experiences.

\section{Research Functions}

a. Helps to provide data for research generalisation.

b. Evaluation clears the doubts for further studies and researches. 
c. Helps to promote action research in education.

\section{Communication Functions}

a. To communicate the results of progress to the students.

b. To intimate the results of progress to parents.

c. To circulate the results of progress to other schools.

\section{Need and Importance of Evaluation}

1. Education has multidimensional programs and activities to inculcate in students a sense of common values, integrated approach, group feelings and community interrelationship which leads to wide level integration and knowledge to adjust in different situations.

2. Evaluation in education measures the effectiveness of value of an educational program which is measured in relation to educational objectives.

\section{Conclusion}

Teaching, learning and evaluation method plays an important role and continuous changes and modification as per requirement enhance the education system. A systematic approach towards planning and execution of educational program is essential for overall development and growth of students, teachers as well as the educational programs. Education being most important component of human beings after survival needs, it requires thorough approach in delivering and receiving education. The success of educational programs require integrated efforts of teachers, students, parent, administrators and managerial members of educational institutions. Society at large provide for and gets benefited by good education. A good education system is a ideal win-win situation for all.

\section{References}

Anderson, A. (2012): The European project semester: A useful teaching method in engineering education project approaches to learning in engineering education.
Journal of Engineering Education, 8:1528.

Bidabadi, N. S.; Isfahani, A. N.; Rouhollahi, A. and Khalili, R. (2016): Effective Teaching Methods In Higher Education: Requirements And Barriers j Adv Med Educ Prof. 4(4): 170-178

Dooge, J. (2007): Engineering training and education. Dublin: Collins Press.

Eberly Center Teaching Excellence \& Educational Innovation

Evaluation in Teaching and Learning Process. http://www.yourarticlelibrary.com/statist ics-2/evaluation-in-teaching-andlearning-process-education/92476.

Khodaparast, H. A. (2005): New perspectives in engineering education: the promotion of traditional models to innovative solutions. Journal of Engineering Education, 7(28):11-22.

Shim, S. H.(2008): A philosophical investigation of the role of teacher: A synthesis of Plato, Confucius, blubber and freire. Teaching and Teacher Education, 24(3): 515-35.

Singh, Y. P. (2009): Editor. Report of the Committee to Advice on Renovation and Rejuvenation of Higher Education. National Seminar on Quality, Expansion and Inclusion in Indian Higher Education; Calicut, India; 1-8. Available from: [http://www.hindu.com/nic/yashpal committee report.] 